\title{
Prácticas otras de conocimiento. Entre crisis, entre guerras
}

doi: http://dx.doi.org/10.32870/espiral.v23i67.5696.g5220

David Velasco Yáñez, sJ•

No resulta sencillo reseñar la riqueza de una obra colectiva que es, verdaderamente, monumental, y que se presenta en tres tomos con el título Prácticas otras de conocimiento(s). Entre crisis, entre guerras. En ella participan medio centenar de autores como Boaventura de Sousa Santos, Sabine Masson, Arturo Escobar, Dana E. Powell, Walter Mignolo, Sylvia Marcos, Charles R. Hale, Aída Hernández, Eduardo Restrepo, María Bertely, Esteban Krotz, Joanne Rappaport, Rafael Sandoval, Mercedes Olivera, Jorge Alonso y muchísimos otros académicos, hombres y mujeres con reconocimiento en México y América Latina, junto con pensadores -también hombres y mujeres- indígenas, magisteriales, estudiantiles, feministas, impulsados por el esfuerzo, la tenacidad y el profesionalismo de Xóchitl Leyva.

Son motivo de celebración los resultados de un esfuerzo de coordinación y de construcción de consensos y voluntades para reivindicar, desde abajo y a la izquierda del campo académico de la antropología, una manera muy otra de producir conocimientos que transforman las realidades de los muchos "sures", conocimientos que pretenden

Profesor-Investigador del Instituto Tecnológico y de Estudios Superiores de Occidente (ITESO). dvelasco@iteso.mx no cambiar el mundo, sino algo mucho más modesto: la construcción de otro mundo en el que quepan muchos mundos.

Xóchitl Leyva, et al. (20I5). Prácticas otras de conocimiento(s). Entre crisis, entre guerras. Tomo II. México: Proyecto Alice, PDTG, IWGIA, Galfisa, Retos. 
El material es muy amplio. Esta reseña se circunscribe a dar cuenta del tomo II. Al iniciar la lectura, surge de inmediato un entusiasmo y una identificación con muchos de los rasgos descritos en esta investigación decolonial, participativa, dialogada y comprometida desde el activismo en y con diversos colectivos.

Particularmente, ha resonado en el autor de la presente reseña su larga trayectoria de más de veinticinco años como educador popular, trayectoria en la cual, de Paulo Freire a Pierre Bourdieu, ha sido el "pan" de todos los días el análisis concreto de la realidad concreta para diseñar estrategias de emancipación.

Conforme se avanza en la lectura del tomo II de la obra aquí reseñada, aparecen las problemáticas de la práctica de una disciplina y su reconocimiento, ya no hecho por los coprotagonistas de las investigaciones y las prácticas otras de conocimiento, sino por el campo mismo de la antropología como disciplina científica.

Al llegar a la descripción del "triángulo de las Bermudas político-científico-institucional actual” que hace Esteban Krotz, este parece un aterrizaje obligado que aparece como sombra en la lectura de los primeros capítulos, pues no se explicita en ellos ninguna de las más básicas condiciones sociales de producción de esa práctica otra de conocimiento, como si fueran productos de la buena voluntad y la excelente disposición de los activistas para iniciar de manera conjunta una investigación antropológica comprometida, decolonial, feminista crítica, y todos los adjetivos que se puedan enunciar para los tres tomos de esta monumental obra.

Por eso, surge la cuestión de si el propósito de establecer el actual orden de presentación tiene un sentido, que puede ir del entusiasmo casi utópico de las posibilidades de una práctica muy otra de la antropología comprometida en la que se explota su enorme potencial subversivo, hasta el análisis crítico, y casi escéptico, de las condiciones objetivas en las 
que se abre paso dicho campo académico. Sin embargo, aun en este análisis crítico de una cierta antropología comprometida socialmente, se visualizan desde un horizonte utópico las posibilidades de mantener y desarrollar el potencial subversivo de la antropología misma.

En ese sentido, parece de la mayor relevancia considerar estas prácticas otras de conocimiento, con toda su variedad, como prácticas de resistencia y rebeldía, abajo y a la izquierda del campo académico de la antropología, que puede fácilmente ubicarse en homología de posiciones con todos los "sures" que habitan este planeta, que representan las cuatro quintas partes de la humanidad.

De aquí surge la relevancia de destacar, entre los diecinueve capítulos que forman este tomo II, las diversas luchas simbólicas que se enfrentan al interior del campo científico ${ }^{1}$ global, en general, y, en particular, del campo de las antropologías. Por eso la importancia y la necesidad de hacer explícita la lucha en contra de una antropología hegemónica y su variante dominante, que no es sólo contra el positivismo de las antropologías anglosajonas, sino también, y sobre todo, contra la "geopiratería" denunciada por Charles. R. Hale, aun cuando no se llegue a la denuncia frontal del uso militar de la antropología que hiciera Gilberto López y Rivas (López y Rivas, 2012) del programa del Pentágono "Iniciativa Minerva" y las expediciones Bowman. ${ }^{2}$

En este punto, no sólo son relevantes las respuestas que se han obtenido al cuestionamiento de las ciencias sociales en tanto ciencias y, por tanto, también de la antropología, sino la denuncia permanente de sus usos militares como un aspecto de la crítica de la razón imperialista, que tiene

I. Aquí se hace referencia al sentido muy preciso que tiene el concepto en la obra de Pierre Bourdieu, El oficio de científico. Ciencia de la ciencia y reflexividad, editada en 2003 en Barcelona por Anagrama.

2. Gilberto López y Rivas publicó varios artículos en el diario La Jornada. Uno en particular, del 12 de septiembre de 2015, citó la obra de Joe Bryan y Denis Wood, Weaponizing maps: indigenous peoples and counterinsurgency in the Americas, del 2015. 
claras objetivaciones en las prácticas de la antropología, en su formación académica y en los usos muy otros de las versiones más radicales de la crítica feminista y la investigación participativa, decolonial y de co-labor.

Las luchas científicas al interior del campo científico se desarrollan desde abajo y a la izquierda y no sólo reivindican la validez científica de las prácticas otras de conocimiento, sino que denuncian los mecanismos, suaves y duros, de la imposición de una ciencia como medida de todas las ciencias, incluyendo la antropología comprometida.

Particular relevancia tiene la descripción que hace Esteban Krotz de ese "triángulo de las Bermudas", contra la democracia que se ha venido imponiendo en las instituciones, no sólo públicas, sino también privadas; contra el dominio de las ciencias naturales sobre las ciencias sociales y su predominio en las instituciones a partir de los esquemas de evaluación, las publicaciones y los programas de estudio, como una forma de organizar la comunidad científica y de generar el conocimiento en todos los campos científicos.

Pero, sobre todo, Krotz llama la atención sobre un planteamiento que hiciera hace casi más diez años Pablo González Casanova sobre la nueva universidad, pues esta está convirtiéndose en una empresa lucrativa y orientada a resolver los problemas de los mercados a través de la generación de un capital de alto valor científico y tecnológico que da lugar a lo que el propio don Pablo llamaba un "capitalismo académico".

Una conclusión relevante y lúcida de Esteban Krotz es que los tres lados del "triángulo de las Bermudas" son aspectos de un mismo proceso: cada uno refuerza a los otros, por lo cual Krotz habla de una necesaria anulación de la antropología mexicana si esta desea sobrevivir en tanto disciplina.

Desde esta visión general del campo científico y, en particular, del campo académico de la antropología, se pueden 
comprender mejor las prácticas otras de conocimiento(s). En primer lugar, porque se puede visualizar una "homología de posiciones" entre la posición dominada del campo académico de la antropología comprometida, decolonial, participativa, dialógica (y todos los adjetivos que se le quieran poner), y la posición dominada en los diversos espacios sociales del conjunto de los condenados de la tierra, para recordar a Franz Fannon, que constituyen el Sur, esa metáfora que expresa el dolor y el sufrimiento de la gran mayoría de la humanidad a causa de un modelo de dominación patriarcal y androcéntrico, extractivista, que explota, despoja, destruye y discrimina.

Desde ese reverso de la historia que el propio Krotz recupera en este tomo II, es relevante establecer este libro como lugar epistemológico radical y no sólo como otra epistemología resultado de la decisión crítica y comprometida de algunos antropólogos.

Por eso, es importante recuperar las diversas y riquísimas experiencias de investigación dialógica que aparecen en este tomo II. Su riqueza no radica solamente en sus contenidos, sino, en particular, en la génesis del compromiso de los académicos y del proceso de conversión de la mirada, no sólo afectiva y emocional, sino, en especial, la del quiebre de las categorías y conceptos dominantes y el surgimientocoproducción de otros saberes.

Algunos capítulos dan cuenta con detalle de estos procesos, y valdría la pena un ejercicio semejante del conjunto de autores, pues el compromiso y el pensamiento crítico no les "cayó del cielo", sino que vivieron un proceso de rupturas y deconstrucciones que, en el marco de las luchas simbólicas del campo de la antropología, son saberes relevantes, al mismo tiempo que permiten ubicar los retos y desafíos actuales para el desarrollo de este campo académico.

En este sentido, el de la genealogía, no sólo de la antropología como campo científico, sino el de la conversión de los 
antropólogos en activistas comprometidos, con un pie en la academia y el otro en el activismo y la militancia, uno de los aspectos más valiosos es el proceso de adquisición de una capacidad de diálogo y, habría que agregar, de empatía con los sujetos coparticipantes de los proyectos de investigación.

No hay uno solo de los capítulos de este tomo II que no mencione, de diversas maneras, la importancia del diálogo como eje fundamental del proceso de construcción del conocimiento, y muchos hacen hincapié en las dificultades y múltiples tensiones que los académicos han aprendido a sobrellevar, a no ocultar y a manejar con paciencia, con enorme respeto a la diversidad de calendarios y geografías, lo que implica tensión con los tiempos y los espacios de la burocracia académica, que tiende a desconocer o ignorar las implicaciones de estos diálogos interculturales.

Finalmente, en este enfrentamiento del "triángulo de las Bermudas" la relevancia del movimiento zapatista es referente obligado de esta producción de conocimientos otros y de la importancia que tiene su difusión y, sobre todo, la multiplicación de estos modos otros de producción de conocimiento.

$\mathrm{Al}$ término de la lectura completa de este tomo II, es obligado hacer el recuento de los grandes retos y desafíos que implica esta manera muy otra de producir conocimientos que son subversivos, que tienden a ser reprimidos, pero que implican un elevado compromiso ético y político.

Estos desafíos los podemos agrupar en dos grandes bloques. El primero tiene que ver con el análisis de los efectos de la dominación simbólica que tan bien describe Gilberto Valdés Gutiérrez y de los cuales hay una expresión emblemática en el trabajo de Manuel Castells en Comunicación y poder. En segundo lugar, y sobre todo, estos análisis tienen que ver con el conocimiento crítico y el desmantelamiento de la nueva vulgata planetaria (Bordieu y Wacquant, 2000) y de sus poderosos instrumentos de producción y circulación 
de las ideas que sostienen y justifican el actual modelo de dominación global y, por lo tanto, también de la ciencia.

En este sentido, es importante, y condición de sobrevivencia, luchar por hacerse un lugar en el campo de la antropología, como una manera legítima de producir conocimientos otros, en medio de la crisis civilizatoria y de la guerra contra los de abajo.

Parte fundamental de estas luchas está en las propias instituciones, públicas y privadas, porque, se quiera o no, la gran mayoría de los autores de esta publicación es parte de las instituciones públicas de investigación y vive de ellas. En este sentido, suena romántico que una de las autoras diga que "nos ganamos la vida escribiendo" (p. 100), cuando en realidad se vive de una plaza y, en ocasiones, también de una beca del Conacyt. La lucha por mantener esos espacios es, quizá, uno de los aspectos más subversivos, dado que es la condición sin la cual no serían posibles estas investigaciones muy otras.

Si al final de esta reseña el lector se siente decepcionado porque no ha sido expuesta la enorme variedad de posibilidades de hacer antropología muy otra, aun en los actuales marcos institucionales, es posible que se anime a explorar en los textos del libro cómo sí es posible, porque ahí está la enorme riqueza de este esfuerzo colectivo, excelentemente coordinado.

Sería ingenuo reducirse a esos testimonios si al mismo tiempo no se destacara que esas prácticas son herederas y protagonistas del ejercicio subversivo y radical de una disciplina que resiste y se rebela a ser domesticada. De ahí que la Escuelita zapatista ha sido y seguirá siendo una fuente de inspiración porque, como lo ha señalado el subcomandante Moisés, hay maneras muy otras de vivir la resistencia y la rebeldía zapatistas ante la hidra capitalista.

No es de otra manera, también abajo y a la izquierda, que la antropología comprometida resiste y se rebela, con 
las armas de la ciencia antropológica, primero, a la dominación de las ciencias naturales sobre las ciencias sociales, y luego al interior de estas a una manera única de hacer antropología.

Por eso, la diversidad de prácticas antropológicas que aquí se presentan, más que luchar entre ellas, tienen su desafío en mirar como miran los zapatistas a la hidra capitalista y, desde ahí, desarrollar su potencial emancipatorio con y desde los oprimidos, asumiendo el método zapatista de avanzar preguntando y de que el problema de la teoría sea un problema práctico.

Bibliografía

Bourdieu, P., y Wacquant, L. (2000). "La nouvelle vulgate planétaire”. Le Monde Diplomatique. Recuperado de: http://www.monde-diplomatique.fr/2000/05/BOURDIEU/2269

López y Rivas, G. (2012). Estudiando la contrainsurgencia de Estados Unidos: manuales, mentalidades y uso de la antropología. México: Semilla Rubí. 